\title{
Use of 3D laser scanning for monitoring the dimensional stability of a Byzantine ivory panel
}

\section{Mona Hess, Capucine Korenberg, Clare Ward, Stuart Robson \& Chris Entwistle}

To cite this article: Mona Hess, Capucine Korenberg, Clare Ward, Stuart Robson \& Chris Entwistle (2015) Use of 3D laser scanning for monitoring the dimensional stability of a Byzantine ivory panel, Studies in Conservation, 60:sup1, S126-S133, DOI: 10.1179/0039363015Z.000000000217

To link to this article: http://dx.doi.org/10.1179/0039363015Z.000000000217
(c) The International Institute for Conservation of Historic and Artistic Works 2015
曲 Published online: 10 Sep 2015.

Submit your article to this journal $\pi$

Џll Article views: 419

Q View related articles $\sqsubset$

View Crossmark data $₫$ 


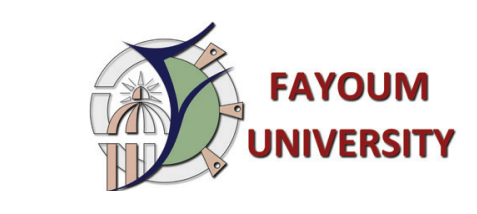

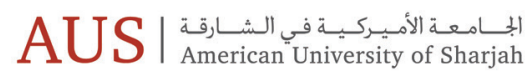

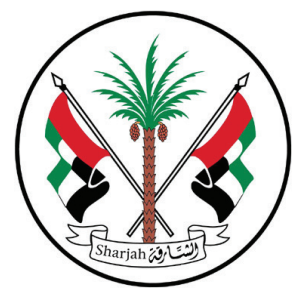

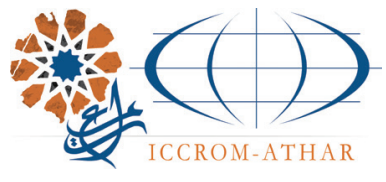

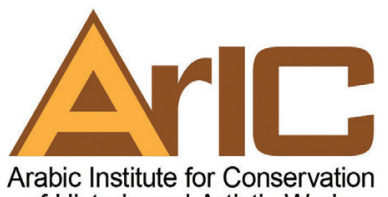
Arabic Institute for Conservation
of Historic and Artistic Works

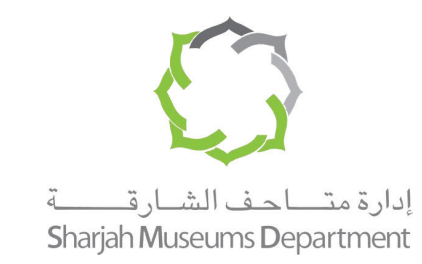

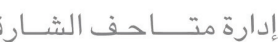

Sharjah Museums Department

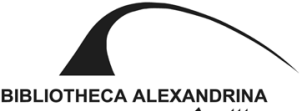

هكتية الإسكزيكر ية

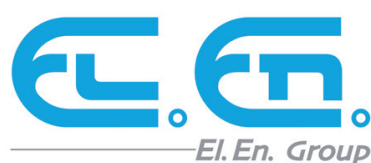

Laser Technologies

SP Pecial

You can sign up for selected content free of charge, and also sign up for table of contents alerts at www.maneyonline.com/sic 


\title{
Use of 3D laser scanning for monitoring the dimensional stability of a Byzantine ivory panel
}

\author{
Mona Hess ${ }^{1}$, Capucine Korenberg ${ }^{2}$, Clare Ward ${ }^{2}$, Stuart Robson ${ }^{1}$, \\ Chris Entwistle ${ }^{2}$
}

${ }^{1}$ UCL Civil, Environmental and Geomatic Engineering (UCL CEGE), London, UK, ${ }^{2}$ The British Museum, London, UK

The British Museum has in its collections a magnificent Byzantine ivory panel. However, the panel has become warped over time and there is a join on the left side, where it has suffered a break in the past. It has been connected with two metal pins and adhesive in a previous conservation treatment but there is now concern that these could be having an adverse influence on natural movements within the ivory. Given the importance of the panel, the decision was made to leave the pins in place and monitor the stability of the panel. As the geometry of the panel is complex, it was felt that microscopic imaging would not be suitable and 3D laser scanning was used instead. This engineering metrology technique is increasingly used in cultural heritage and conservation to record minute three-dimensional changes with high spatial accuracy. The resulting dataset is a detailed metric 3D record of the object surface inthe-round and comparison of subsequent scans with a reference scan can indicate dimensional changes. As part of a monitoring campaign, the ivory panel was first scanned in January 2012 to provide a reference scan. It was then scanned again in autumn 2012 (no significant movement was detected) and will be scanned at regular intervals in the future. This case study demonstrates the potential of 3D laser scanning to monitor the dimensional stability of complex artefacts.

Keywords: Examination method, 3D laser scanning, Ivory, Deformation, Monitoring, Dimensional stability

\section{Introduction}

This case study applies high-resolution 3D laser scanning to one of the most important early Byzantine objects belonging to the British Museum: an ivory panel showing the Archangel Michael holding a sceptre and orb surmounted by a jewelled cross (registration number: OA 9999), see Fig. 1A. The ivory panel was made in approximately AD 525-550 and its dimensions are $428 \mathrm{~mm}$ (length), $143 \mathrm{~mm}$ (width), and $9 \mathrm{~mm}$ (thickness). The ivory has been identified as elephant ivory (Cartwright 2014). The panel has become warped over time and suffered a break. The break was repaired by conservators using pins and an adhesive in 1954, but there are concerns about the stability of the panel. As the geometry of the panel is complex, it was felt that microscopic imaging would not be suitable to monitor its stability and it was decided to investigate whether 3D laser scanning, an optical surface recording technique,

Correspondence to: Mona Hess, UCL CEGE, Chadwick Building, Gower Street, London WC1E 6BT, UK. Email: m.hess@ucl.ac.uk. could be used instead. A collaborative project was started in 2012 between The British Museum and UCL to monitor the stability of the panel using 3D laser scanning. This technology, which comes from engineering metrology, is increasingly used in cultural heritage and conservation to record minute threedimensional changes with high spatial accuracy (see for instance Hallet et al., 2008 and Hallet \& Robert, 2013).

\section{The ivory panel}

Provenance, significance, and material

It is one of the two leaves of a diptych, and is the right leaf, the left leaf being lost. This object came into the possession of the British Museum in the nineteenth century with no further information about its provenance. It is one of the largest Byzantine ivory panels to have survived and is therefore an object of high art-historical significance. The front is intricately carved with three-dimensional architectural elements in the upper part, a flower shape and a richly decorated niche over St Michael. Fluted decorated 

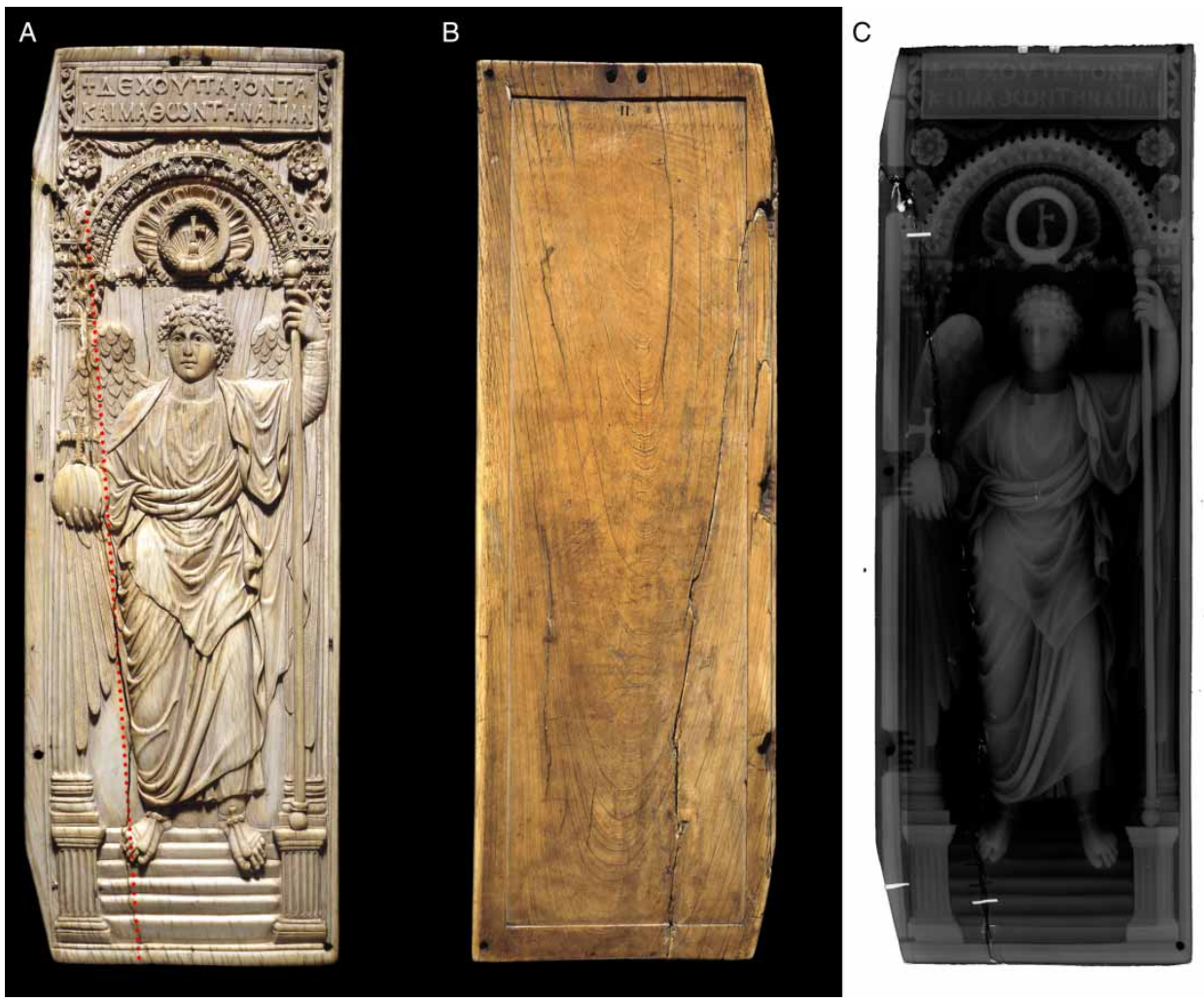

Figure 1 (A) Front of the ivory panel. The approximate location of the break is shown by a red dashed line. (B) Back of the ivory panel. (C) X-ray of the ivory panel showing the metal pins in white. (Copyright: Trustees of the British Museum.)

columns frame the Archangel, who wears a Greek tunic, holds an orb and a staff and stands at the top of a flight of stairs. It is thought that the left leaf might have depicted Emperor Justinian (reign: AD 527-565), to whom the insignia (orb and staff) would be offered. The artefact is attributed to the imperial workshop in Constantinople. The back of the panel shows a faded ink inscription in Greek. Byzantine ivories were often decorated with polychromy and gilding. However on this object there does not appear to be any evidence of applied decoration (Ambers \& Russell, 2013). The craftsmanship and beauty of this object are exceptional. Further information on the panel and its significance is available on the British Museum online database (British Museum, 2013) and from Buckton (1994).

At the beginning of the project the ivory was on display in a showcase conditioned at $50 \%$ relative humidity ( $\mathrm{RH}$ ) (daily variation $< \pm 5 \% \mathrm{RH}$ ). It was mounted vertically and held in place by covered pins.

\section{Conservation condition}

The panel has warped over time and its condition is fragile. It has a longitudinal fracture running along the laminae structure of the ivory on the proper right side of the panel (see Fig. 1A and B). It is not known when the longitudinal break through the object might have developed, but it is suspected that it appeared during storage in an unconditioned environment in the early twentieth century due to the heating of rooms from that period onwards. Conservation records from 1954 state that metal pins were used to join the parts at two points across the join. These are also visible in an X-ray of the object (Fig. 1C). A cellulose nitrate adhesive, Durofix, has been applied in two places and the gap has been left open in case 'the gap closes naturally' according to the conservation record. The small acrylic fill in the join at the point where the orb is held in the angel's right hand was added in about 2007 for aesthetic reasons and also to give additional support across the join.

Due to the warping, the two parts of the join align only at the top and bottom. There is now concern that the metal pins could be having an adverse influence on natural movements within the ivory. But the removal of the pins could be damaging to the object and it was decided to monitor the stability of the panel.

\section{Background - metric and dimensional monitoring of organic materials}

Ivory, as a material, is both hygroscopic and anisotropic and so expands and contracts by different amounts in different directions in response to changes in $\mathrm{RH}$ and temperature. This causes a build-up of stress in the ivory and can result in cracks and breakage (Lafontaine \& Wood, 1982). 
Specific monitoring procedures for preventive conservation and during ongoing conservation have already been applied to wood panels and panel paintings. Small deformations of organic material and objects can be measured through hygro-mechanical monitoring (Allegretti et al., 2013). Another method is the careful installation of reference points on the object, followed by distance measurement using dial gauges and digital Vernier callipers at regular intervals (Allegretti et al., 2014). Methodologies for dimensional monitoring using surface imaging are known and have been tested by Boochs et al. (2008) and Guidi et al. (2007). Non-contact deformation monitoring by photogrammetry was demonstrated by Robson et al. (2004).

While 3D laser scanning is no more exact than microscopic imaging (with $10 \times$ magnification and higher), the ivory panel has a complex surface that would make it difficult to capture the warping accurately using a 2D method. On the other hand, 3D laser scanning should allow monitoring of the movement of the plaque in the round in all axes of movement. This allows a much better evaluation of the change in 3D shape of the material than microscopy or 2D photography from just front and back. Observation about material-typical dimensional changes and deformation, quantified radial movement, and reversible deformation can be quantified and demonstrated. To our best knowledge, scientific projects using close range $3 \mathrm{D}$ imaging with the aim of monitoring the spatial stability of organic materials, such as ivory, have so far not been pursued.

\section{Experimental}

\section{$2 D$ image analysis}

Alongside the 3D imaging project and for a visual and qualitative understanding of the object, existing orthographic documentation photographs and $\mathrm{X}$-radiographs were superimposed for the back and front. This allowed layers with line traces of the ivory laminae to be created for both sides. It also enabled the position of laminae and the join from back and front to be correlated (see Fig. 2).

At the time of manufacture the overall shape of the ivory would have been flat or with only a slight natural curvature. It is assumed to have changed over time and warped, both in longitudinal and in transverse direction with the edges on each side deflecting towards the back.

\section{$3 D$ analyses}

A 3D colour laser scanner, Arius3D Foundation Scanner 150 by Arius Technologies, was used in a laboratory set-up at UCL. The system comprises a scan head delivering $3 \mathrm{D}$ coloured point data at a sampling interval of $0.1 \mathrm{~mm}$ (approximately 250 dots per inch).
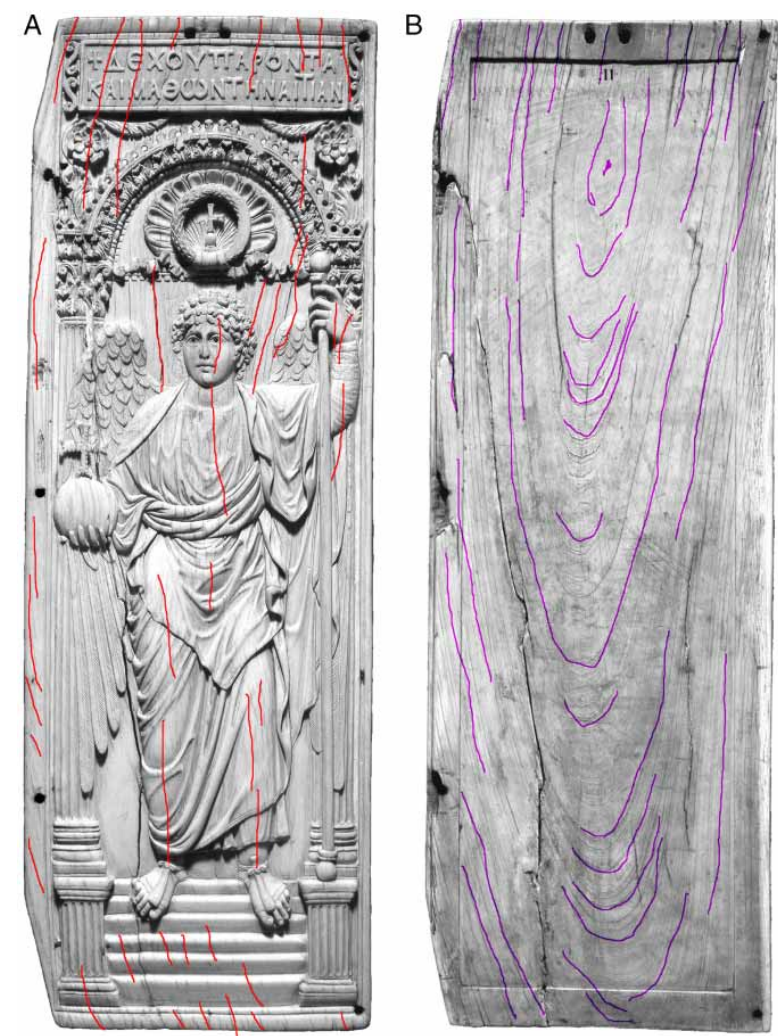

Figure 2 Line traces of the ivory laminae: $(\mathrm{A})$ at the front and (B) at the back.

The scan head is mounted onto a coordinate measurement machine allowing robotic movement over the surface of small objects in a laboratory maintained at $50 \% \mathrm{RH}( \pm 3 \%)$ and $20^{\circ} \mathrm{C}$ (maintaining a stable $\mathrm{RH}$ is essential as ivory is hygroscopic). A custommade mount was provided for the ivory panel and mounted onto a goniometric stage allowing the setting of precise angles for repetitive angular recording of the panel. For this object, the stage was tilted by $10^{\circ}$. The advantage of this methodology is that both measurement and manipulation of the panel are non-contact and therefore suitable for use with fragile or sensitive objects. Object handling, for example to turn the object around to scan the back, is usually conducted by museum staff or a trained operator.

The monitoring of this ivory object uses existing optical 3D surface imaging methods to establish datasets for the dimensional comparison of a baseline image (reference dataset) and multiple datasets taken after the baseline image. Measurement uncertainty of the sensor is $\pm 0.035 \mathrm{~mm}$ in depth (z-axis) and of the order of $\pm 0.1 \mathrm{~mm}$ in the $\mathrm{x}$ - and $\mathrm{y}$-axes due to planimetric point spacing and laser spot size. The planimetric uncertainty dominates the geometric alignment necessary to compare different scans with the result that the accumulated error is of the order of $\pm 0.1 \mathrm{~mm}$ in all three axes. Significant surface detail can be recorded with twice the sampling 
distance, i.e. at $0.2 \mathrm{~mm}$ spatial or structural resolution. Movements can then be visualised, interpreted, and interactively explored in a $3 \mathrm{D}$ viewer in direct relation to the object surface through a graphical deviation map overlaying the $3 \mathrm{D}$ image. For the reference dataset, the six faces of the panel were scanned. In subsequent scans, only the front and back of the panel were scanned. All data (including raw data) were given to the British Museum with the understanding that it can also be used for non-commercial purposes by UCL CEGE. The copyright on the datasets resides with the British Museum. As ivory is hygroscopic, the panel was kept at $45-55 \%$ RH during transport and in the 3D scanning lab at UCL.

\section{Preliminary tests}

With the help of a machined sample of modern elephant ivory (see Fig. 3), it was ascertained that 3D colour laser recording of an ivory surface can be successfully conducted to meet the data quality

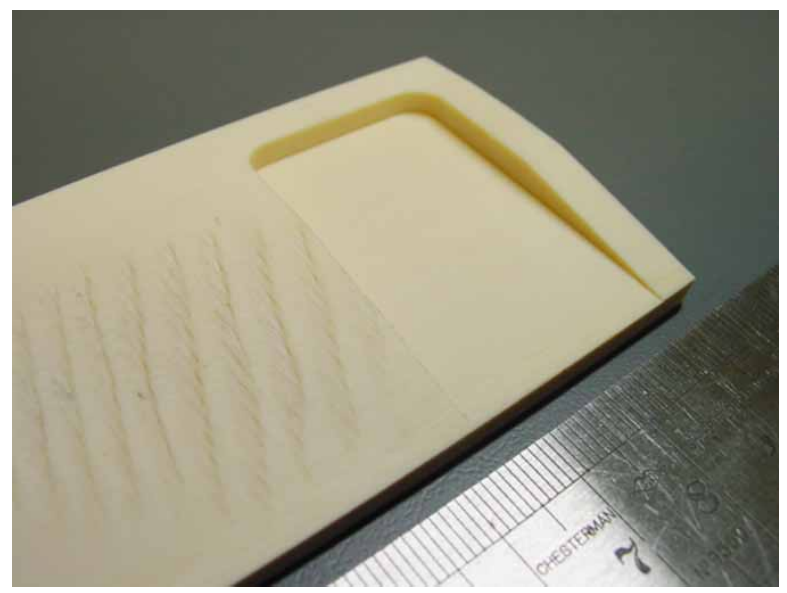

Figure 3 Elephant ivory sample piece with milled 'flat'. requirements. A geometry comparison to a fitted plane (3 sigma Gaussian fit) confirmed that the sensor was performing to its specifications with $\pm 0.035 \mathrm{~mm}$ deviation from the machined plane, see Fig. 4A. Furthermore, the tooling marks of the Computer Numerical Control mill could be seen in the 3D scan, which are not immediately apparent to the naked eye (Fig. 4B). We can therefore conclude that minute details on the ivory can be recorded by 3D laser scanning.

\section{Results}

The first baseline image was recorded in January 2012. It will be called 'reference data' in the following analysis. It was initially planned to scan the panel approximately six months later but due to a fault with the conditioning equipment in the scanning laboratory, this had to be delayed until November 2012. Technical problems with the scanner meant that the panel was actually scanned again in December 2012.

The results are shown in Figs 5-7 as colour coded deviation maps. The bar on the side of each figure shows a line with the error distribution from 0.05 to $-0.05 \mathrm{~mm}$ with a characteristic Gaussian histogram showing deviation errors peaking around zero; the coloured bar shows the numeric to colour assignment of the deviation error (positive and negative), which can be seen on the surface of the $3 \mathrm{D}$ scan.

\section{Reference scan}

The reference scan of the ivory panel was recorded over two days (11-12 January 2012). All scanning was executed at 100 micron grid resolution. A dense 3D coloured point cloud was created which shows manufacturing details and material colours (Fig. 5A). A 3D digital image of the ivory plaque was successfully created with only some minor areas

A

B

Day 1 Deviation to Plane (Gaussian 5 Sigma Plane fit). +/- 0.03 , as expected from system specifications,

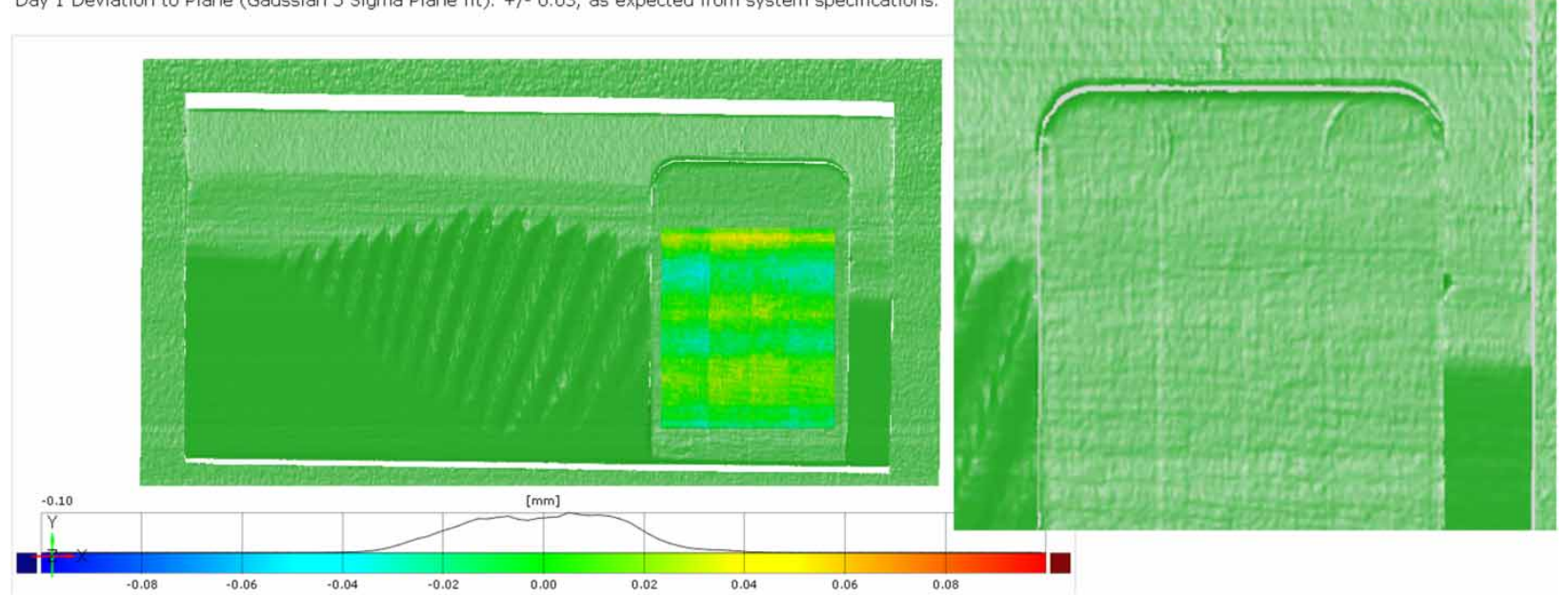

Figure 4 (A) Three-dimensional image of ivory sample deviation of flat from plane. The image shows a 3D scan of ivory flat $\left(20^{\circ} \mathrm{C}\right.$ at $50 \% \mathrm{RH}$ ). (B) Detail of 3D scan of the milled surface showing manufacturing traces. 


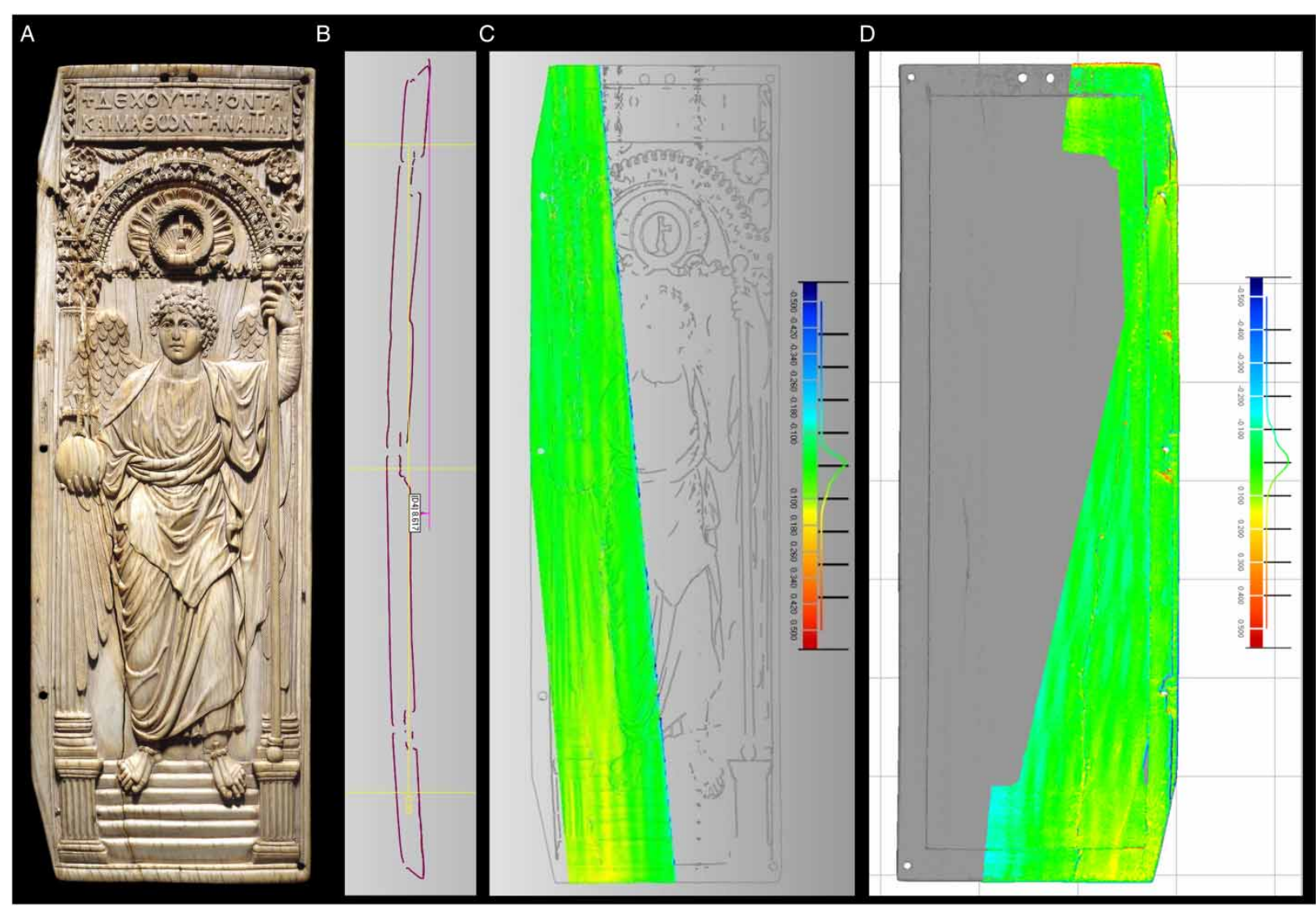

Figure 5 (A) Three-dimensional coloured point cloud of the surface; (B) cross section through proper right side, showing warping of $8 \mathrm{~mm}$; comparison between 11 January 2012 and 12 January 2012 scans, (C) front and (D) back.

missing due to occlusions caused by the intricate and undercut geometry of the surface. However, a complete surface recording was not the main aim of the monitoring task. The model shows that the ivory panel is warping upwards, towards the carved front, with a maximum deflection of $8 \mathrm{~mm}$ in the centre of the long side, when measuring the distance between the edges and the centre (Fig. 5B). This high-resolution $3 \mathrm{D}$ model will be stored at the museum for long-term digital preservation and use in the museum's collection database. A lower resolution version of the $3 \mathrm{D}$ image will be on the British Museum website aimed at public engagement.

To test the accuracy of the methodology when comparing scans, the area around the join was scanned on each day. As expected, the difference between the two scans was no more than 100 microns, which is due to the error of alignment between different passes (Fig. 5C and D). However, this means that any movement in the join less than 100 microns cannot be detected using 3D scanning. To monitor the break area with higher accuracy, a different methodology specific for gap measurements would need to be employed, such as a slit laser beam profiler. Note that the measurement of the gap with tactile means, such as a gauge, is not recommended due to the delicacy of the material.

\section{Subsequent scans (autumn 2012)}

In November 2012, the surface was recorded for comparison of overall shape, but repeated technical problems with the scanning hardware resulted in a sampling interval of 200 and 300 microns (instead of the 100 microns of the reference scan) being used. This dataset is incomplete at the back, but capture of the proper right side of the front and all corners was achieved as well as the proper right side of the back. Comparing this dataset with the reference scan shows a deviation of up to -400 microns on the front bottom left edge and all along the front proper right edge (dark blue colour in Fig. 6A), which indicates a negative or downward movement of the front edges in relation to the middle of the panel. The back shows an asymmetrical deformation around the bottom proper right edge (indicated in yellow and orange in Fig. 6B). However, because of the large sampling interval, this scan does not capture small details around the break area and the scanning process was repeated the following month.

The dataset from December 2012 only recorded the area around the break on the front and again had technical difficulties when recording the back of the panel, i.e. there were data drop-outs. Patchy data caused difficulties of correct alignment of data on the back 


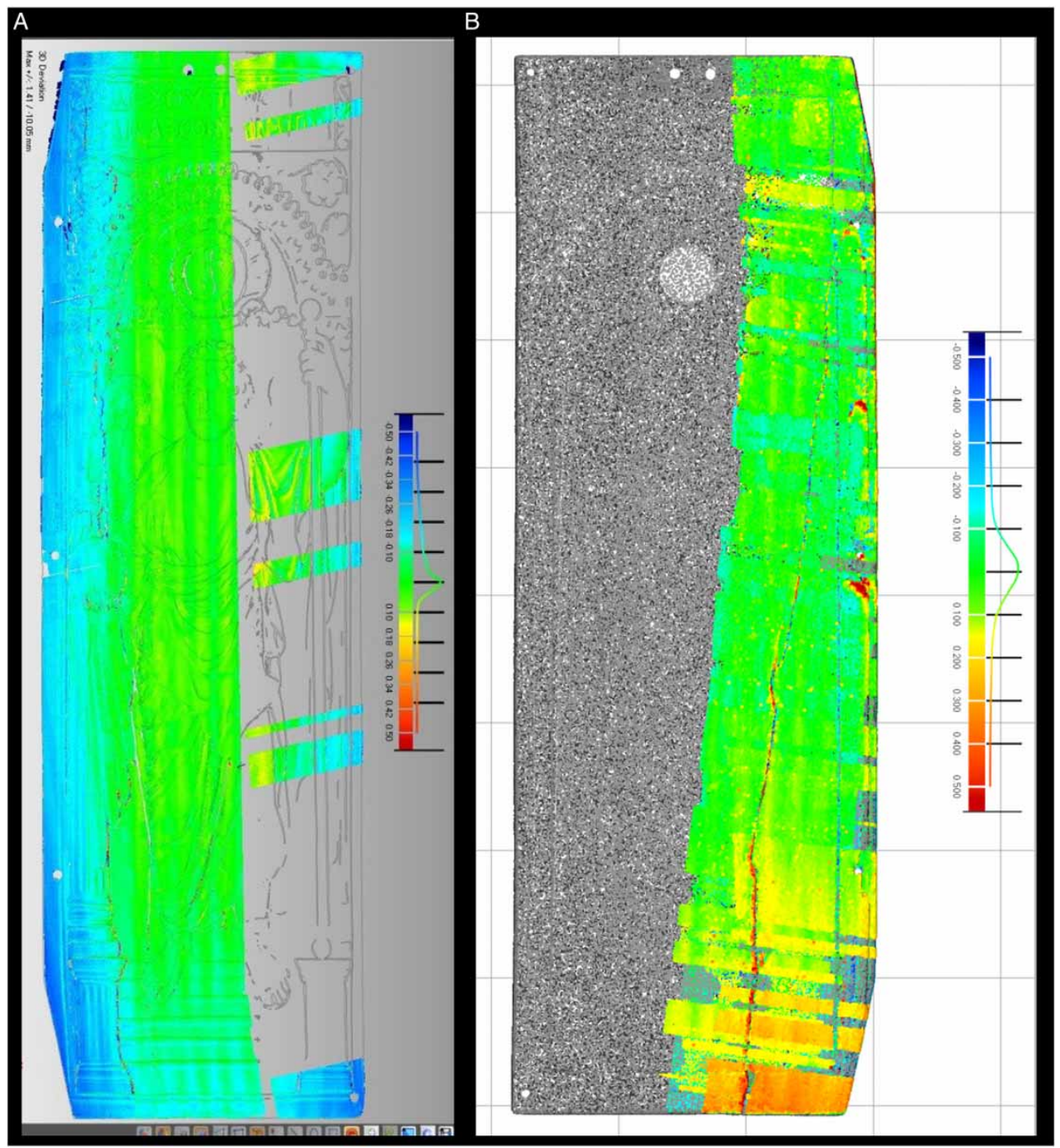

Figure 6 Comparison between 11 January 2012 and 19 November 2012. Scans from (A) front and (B) back of the panel.

(Fig. 7B). However, no significant movement in the panel was detected when comparing the front scan to the reference scan (Fig. 7A): in fact, this scan is similar to the reference scan within the planimetric scan point spacing of 100 microns. The agreement between these two datasets indicates that the backwards deformation along the edges measured in November is not a permanent deformation. This movement could have been caused by small variations in $\mathrm{RH}$ as ivory is hygroscopic.

\section{Summary of results}

No significant movement has occurred between January 2012 and November-December 2012 that would suggest ongoing damage to the object, but a reversible backward movement on the edges of the front of the panel was observed, possibly due to the response of the ivory to small changes in RH. This observation led to the decision to change the way the object would be displayed in its new showcase. Originally mounted vertically, it was decided to display the ivory plaque in the
Sutton Hoo and Europe Gallery at an angle to minimise internal stress (see Fig. 8). This gallery was reopened in March 2014 after complete refurbishment.

\section{Conclusions}

Three-dimensional colour laser scanning was successfully used to create a digital image of an intricately carved ivory panel and monitor movement to an accuracy of the order of 100 microns. While this methodology of optical surface imaging is not more exact than microscopic imaging (with $10 \times$ magnification and higher), it is capable of recording the movement of a complex object in all axes of movement, which would be impossible using conventional techniques. This allows a much better evaluation of the change in 3D shape of an object with a complex surface over time. No significant permanent changes in shape were detected in the ivory panel between January 2012 and autumn 2012. Further monitoring sessions are planned for the future, starting in autumn 2014. Despite 


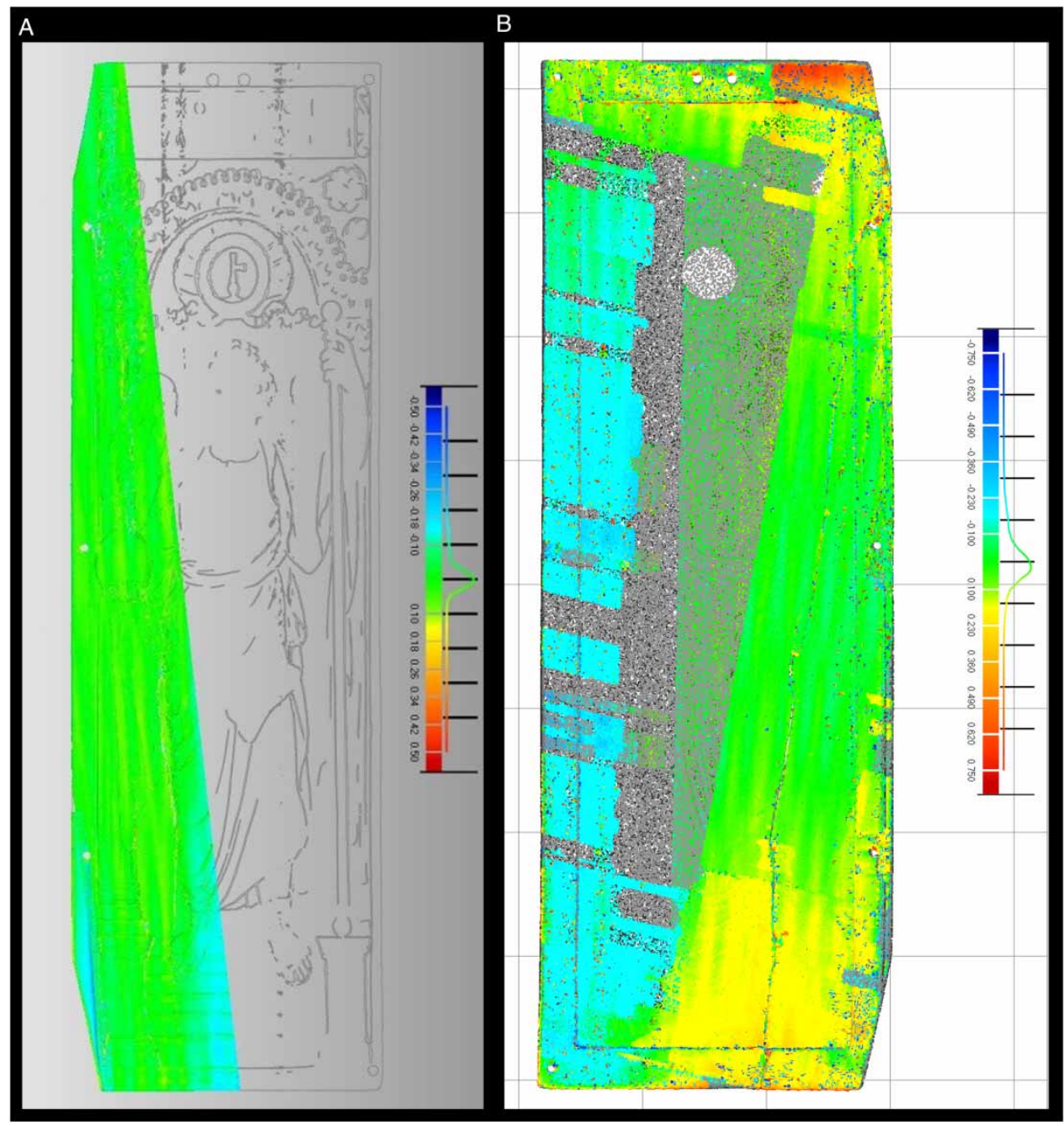

Figure 7 Comparison between 11 January 2012 and 19 December 2012. Scan from (A) front and (B) back of the panel.

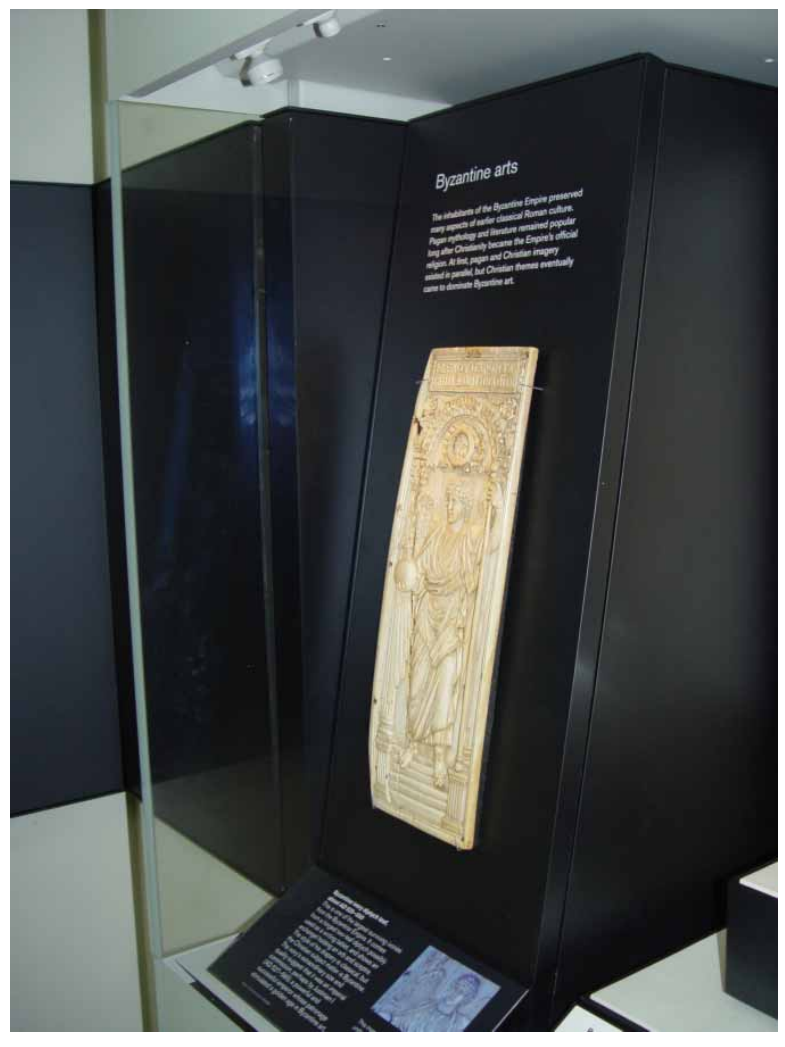

Figure 8 New display of the Byzantine ivory panel. technical difficulties, this case study demonstrates the potential of $3 \mathrm{D}$ laser scanning to monitor the dimensional stability of complex artefacts.

\section{Future work}

Further research around the monitoring of organic material is planned in future, in particular to test the dimensional changes of objects when exposed to humidity and temperature changes. There was large interest by other delegates at the Lacona X conference (Lasers in the Conservation of Artworks) and the system and set-up were recognised as having strong potential. There is also scope to adapt this methodology for further work by the two project partners.

\section{Acknowledgements}

Many thanks to Duygu Camurcuoglu, Conservator for carrying out the X-radiography of the plaques, also James Peters, Senior Museum Assistant for the preparation of the support on which the plaque was scanned. 


\section{References}

Allegretti, O. et al. 2013. Long-Term Hygromechanical Monitoring of Wooden Objects of Art (WOA): A Tool for Preventive Conservation. Journal of Cultural Heritage, 14(3): 161-64.

Allegretti, O. et al. 2014. The Influence of Dovetailed Cross Beams on the Dimensional Stability of a Panel Painting from the Middle Ages. Studies in Conservation, 59(4): 233-40.

Ambers, J. \& Russell, J. 2013. Technical Imaging of Ivory Plaque OA 9999. British Museum Internal Report 2013/10. London: British Museum.

Boochs, F., Huxhagen, U. \& Kraus, K. 2008. Potential of High-precision Measuring Techniques for the Monitoring of Surfaces from Heritage Objects. In: International Workshop In-situ Monitoring of Monumental Surfaces. Florence.

British Museum 2013. Explore British Museum Highlights Online: Ivory Panel Showing an Archangel, accession number M\&ME OA 9999. [accessed 15 August 2014] Available at: $<$ http://www.britishmuseum.org/explore/highlights/high light_objects/pe_mla/i/ivory_panel_with_archangel.aspx $>$

Buckton, D. 1994. Byzantium: Treasures of Byzantine Art and Culture from British Collections British Museum, ed., London: Published for the Trustees of the British Museum by British Museum Press.

Cartwright 2014. [personal communication] Identification of OA999, British Museum, as elephant ivory.
Guidi, G., Beraldin, J.-A. \& Atzeni, C. 2007. Wood Artworks Dimensional Monitoring through High-resolution 3D Cameras | Publications: SPIE. [accessed 15 August 2014]. Available at: <http://spie.org/x648 .html?product_id=705332>.

Hallet, Z. \& Robert, Z. 2013. 3D Laser Digitization for the Condition Monitoring of the Da Maiano Terracotta Roundels - Five Years on. In: D. Saunders et al., eds. Lasers in the Conservation of Artworks IX. London: British Museum, Archetype, pp. 154-62. [accessed 15 August 2014]. Available at: $\quad<$ http://www.archetype.co.uk/publication-details php?id=173>

Hallet, Z., Robert, Z. \& Julien-Lee, S. 2008. High-resolution 3D Laser Digitisation of the Maiano Terracotta Roundels for Documentation and Condition Monitoring. In: M. Castillejo et al., eds. Lasers in the Conservation of Artworks: Proceedings of the International Conference Lacona VII, Madrid, Spain, 17-21 September 2007. CRC Press, pp. 413-18.

Lafontaine, R.H. \& Wood, P.A. 1982. The Stabilization of Ivory against Relative Humidity Fluctuations. Studies in Conservation, 27(3): 109-17.

Robson, S. et al. 2004. Periodic Photogrammetric Monitoring and Surface Reconstruction of a Historical Wood Panel Painting for Restoration Purposes. In: International Archives of Photogrammetry and Remote Sensing. Istanbul: ISPRS. 